\title{
Article \\ Characterization of AlSi10Mg- CP-Ti metal-metal composite materials produced by electro-sinter-forging
}

\author{
Federico Simone Gobber 1,4*, Elisa Fracchia ${ }^{1,4}$, Alessandro Fais ${ }^{2}$, Ildiko Peter ${ }^{3 *}$, Marco Actis Grande1, \\ 1 Department of Applied Science and Technology (DISAT), Polytechnic of Turin, Viale T. Michel 5, 15121 \\ Alessandria, Italy; federico.gobber@polito.it (F.S.G.); elisa.fracchia@polito.it (E.F.); marco.actis@polito.it \\ (M.A.G.) \\ 2 Epos s.r.l., Via Pavia 68/72, 10098 Rivoli, Italy; af@eposintering.com (A.F.) \\ 3 Department of Industrial Engineering and Management, Faculty of Engineering and Information Technol- \\ ogy, University of Medicine, Pharmacy, Science and Technology “George Emil Palade" of Târgu Mureș, str. \\ N. Iorga nr. 1, 540139 Targu Mures, Romania, ildiko.peter@umfst.ro (I.P.) \\ 4 Consorzio INSTM, Via G. Giusti 9, 50121 Firenze, Italy \\ * Correspondence: ildiko.peter@umfst.ro (I.P.); federico.gobber@polito.it (F.S.G.).
}

\begin{abstract}
Metal/metal composites represent a particular class of materials showing innovative mechanical and electrical properties. Conventionally, such materials are produced by severely plastically deforming two ductile phases via rolling or extruding, swaging, and wire drawing. This study presents the feasibility of producing metal/metal composites via a capacitive discharge-assisted sintering process named electro-sinter-forging. Two different metal/metal composites with CP-Ti/AlSi10Mg ratios (20/80 and 80/20 \%vol) are evaluated, and the effects of the starting compositions on the microstructural and compositional properties of the materials are presented. Bi-phasic metal/metal composites constituted by isolated $\alpha$-Ti and AlSi10Mg domains with a microhardness of $113 \pm 13 \mathrm{HV}_{0.025}$ for the Ti20-AlSi and $244 \pm 35 \mathrm{HV}_{0.025}$ for the Ti80-AlSi are produced. The effect of the applied current is crucial to obtain high theoretical density, but too high currents may result in Ti dissolution in the Ti80-AlSi composite. Massive phase transformations due to the formation of AlTiSi based intermetallic compounds are observed through thermal analysis and confirmed by morphological and compositional observation. Finally, a possible explanation for the mechanisms regulating densification is proposed accounting for current and pressure synergistic effects.
\end{abstract}

Keywords: AlSi10Mg; CP-Titanium; Electro-Sinter-Forging; Metal-metal Composites.

\section{Introduction}

Aluminum and Titanium alloys are widely used in automotive applications due to their specific properties. Al and its alloys are characterized by high specific strength, good stiffness, and good wear resistance [1], whereas Ti and its alloys exhibit high specific strength and stiffness, very high corrosion resistance, and biocompatibility. These properties make $\mathrm{Ti}$ an excellent choice for applications that range from biomedical to aerospace [2]. However, several properties of aluminum alloys can be improved by adopting an Albased composite material [3,4]. Composite materials consist of two or more different materials: a matrix and a strengthening phase. Matrixes can be organic, metallic, or ceramic, and the final achievable properties are usually a combination of properties of the single materials adopted.

Singh et al. [3] summarized the possible techniques for developing metal-matrix composites: stir casting, centrifugal casting, squeeze casting, and powder metallurgy. This latter is highly important for the production of net-shape and near-net-shape components [4]: it is a flexible manufacturing process capable of delivering a wide range of materials, producing high-quality complex parts to close tolerances in a cost-effective way [5]. 
Metal-metal composites can be adopted to overcome the characteristic drawbacks of metal/ceramic composites, such as weak interface bonding between the metal and the ceramic straightening particles or the low ductility. In addition, these types of composites have improved machinability and minor porosity compared to a ceramic strengthening phase. Furthermore, new and innovative materials may be realized by balancing their properties as a function of the amount and type of metals involved [6,7].

In [8], Canakc1 et al. produced a high-performance metal-metal composite of AA2024 and 316L through milling and hot pressing. Various Fe-Al intermetallics, detected by Xray diffraction analysis, played a critical role in the pitting corrosion enhancement. In [9], Gopi Krishna et al. produced a composite material using two Al alloys: AlSi7Mg0.3 and a high strength Al20Cu10Mg alloy. The authors observed an increase in density by the increasing percentage of reinforcements (from 5\% to $15 \%$ ), while the resistivity decreased from $25 \mathrm{n} \Omega-\mathrm{m}$ to $11 \mathrm{n} \Omega-\mathrm{m}$ with $5 \%$ and $15 \%$ of reinforcement, respectively. Moreover, the reinforcement improved the hardness, thanks to the formation of intermetallic phases such as $\mathrm{CuMgAl}_{2}$. Other studies successfully developed intermetallic compounds between $\mathrm{Al}$ and Ti starting from the pure elements or pure Ti and an Al alloy. In [10], Sun et al. highlight how to fabricate Ti-Al compact by spark plasma sintering from elemental foils of CP-Ti and CP-Al. This process led to a multilayered dense metal-metal composite in Ti-Al having variable microstructures depending on the sintering conditions. After a pre-sintering at $450^{\circ} \mathrm{C}$, no reaction was observed between $\mathrm{Ti}$ and $\mathrm{Al}$, while after heat-treating at $900^{\circ} \mathrm{C}$, few $\mathrm{Ti}_{3} \mathrm{Al}, \mathrm{TiAl}, \mathrm{TiAl}_{2}$, and $\mathrm{TiAl}_{3}$ intermetallic phases nucleated from molten Al. By increasing the plasma spray sintering temperature, homogeneous Ti-Al intermetallics-based alloys were obtained. These multilayered Ti/Ti-Al intermetallics compacts exhibited very high flexural strength and toughness of $1400 \mathrm{MPa}$.

In [11], $\mathrm{Ti}-\mathrm{Al}_{3} \mathrm{Ti}$ laminated composites have been prepared with $\mathrm{Ti}$, using $\mathrm{Al}$ foils having different initial thicknesses. The composite resulted well bonded and fully dense, and the reaction between the molten $\mathrm{Al}$ and $\mathrm{Ti}$ led to the formation of intermetallic phase $\mathrm{Al}_{3} \mathrm{Ti}$ intermetallic layers. Similarly, in [12], cold rolling and annealing were used to realize sandwich-like Ti-Al metal-metal composites, starting from commercially pure sheets. Due to the annealing process, the composites obtained were characterized by $\mathrm{TiAl}_{3}$ intermetallic phases that nucleate and grow with a linear kinetics mechanism.

Huang et al. [13] report a study related to a layered $\mathrm{Ti} / \mathrm{Al}$ composite manufactured through hot pressing and hot rolling. The tensile properties of such composites agree with the rule of the mixture, with an Ultimate Tensile Strength (UTS) of $250 \mathrm{MPa}$, while its ductility is higher than the ductility of the single alloy.

Currently, there are no studies regarding the densification of metal-metal composites via sintering techniques based on capacitive-discharge in literature: for this reason, Electro-Sinter-Forging (ESF) was chosen. Besides being an emerging near-net-shape technology with high potentialities in terms of productivity and environmental footprint control [14], there are several studies in literature exploiting the potentialities of ESF in the manufacturing of a wide range of metals and alloys such as precious alloys metals parts [16], memory shape alloys [17] and steels [16,18].

The process is relatively simple: a mechanical pulse is superimposed onto an electrical one in a die with tight geometrical tolerance previously loaded with the powders. A capacitor bank originates the electrical pulse at high voltage; then, a transformer raises the current and lowers the voltage. The electromagnetic discharge is synchronized to the mechanical impulse so that energy is transferred just after reaching a set pressure level; this guarantees a homogeneous flow of current through the powders. The mechanical pressure compensates for the powder shrinkage during sintering; for this reason, it is raised when the electromagnetic energy is transferred through the powders. The pressure is held from a few ms up to 1-3 s, then the upper plunger is automatically drawn out of the die, and the lower plunger is moved to the upper part of the die to extract the sintered piece. 
From a previous study on the cold rolling of an ESFed CuSn15 bronze [19], the authors observed the presence of non-alloyed domains constituted by pure $\mathrm{Cu}$ in the densified material as a side-effect of admixing pure $\mathrm{Cu}$ powders to the $\mathrm{CuSn}$ ones. Thus, the experience with CuSn15 suggested the possibility of adopting ESF to densify structures where metals having high solubility or that tend to form intermetallic compounds are present in their original metallic form. For this reason, the consolidation of Ti/Al-alloy metal-metal composites is explored in this research.

In the present research paper, AlSi10Mg/CP-Ti metal-metal composites were produced by Electro-Sinter-Forging (ESF) to create a well-bonded composite without the nucleation of significant intermetallic phases. As a result, two composites are obtained: one characterized by CP-Ti matrix and AlSi10Mg second phase (hereafter named Ti80-AlSi), while the second type has AlSi10Mg as the matrix and CP-Ti as the second phase (hereafter named Ti20-AlSi). The effects of AlSi10Mg and CP-Ti contents on the metal-metal composites' microstructure, phase composition, and microhardness were considered for each type of material. The properties of the metal-metal composites have been characterized by differential scanning calorimetry, elemental analysis for light elements such as $\mathrm{O}, \mathrm{N}, \mathrm{H}$, C, and S, X-ray diffraction, and microstructural analysis.

\section{Materials and experimental methods}

\subsection{Materials and sample production}

Disc-shaped samples with $15 \mathrm{~mm}$ diameter and nominal $5 \mathrm{~mm}$ thickness were consolidated via ESF. Commercially pure (CP) Ti-Grade2 powders (Metco 4013A with 45 $106 \mu \mathrm{m}$ PSD and $2.4 \mathrm{~g} / \mathrm{cm}^{3}$ tap density) and AlSi10Mg powders (Ecka Germany $\mathrm{GmbH}$, Alumix, with $10-160 \mu \mathrm{m}$ PSD and $1.6 \mathrm{~g} / \mathrm{cm}^{3}$ tap density) were mixed and then densified. The applied pressure (MPa) and the intensity of the electric impulse (kA) discharged on the powders were progressively increased from one sample to the subsequent one to reach the theoretical density. In Figure 1, a processing map is drawn for the experiments performed: the applied energy reported on the x-axis is the reference process parameter obtained from the time integration of the current pulse.

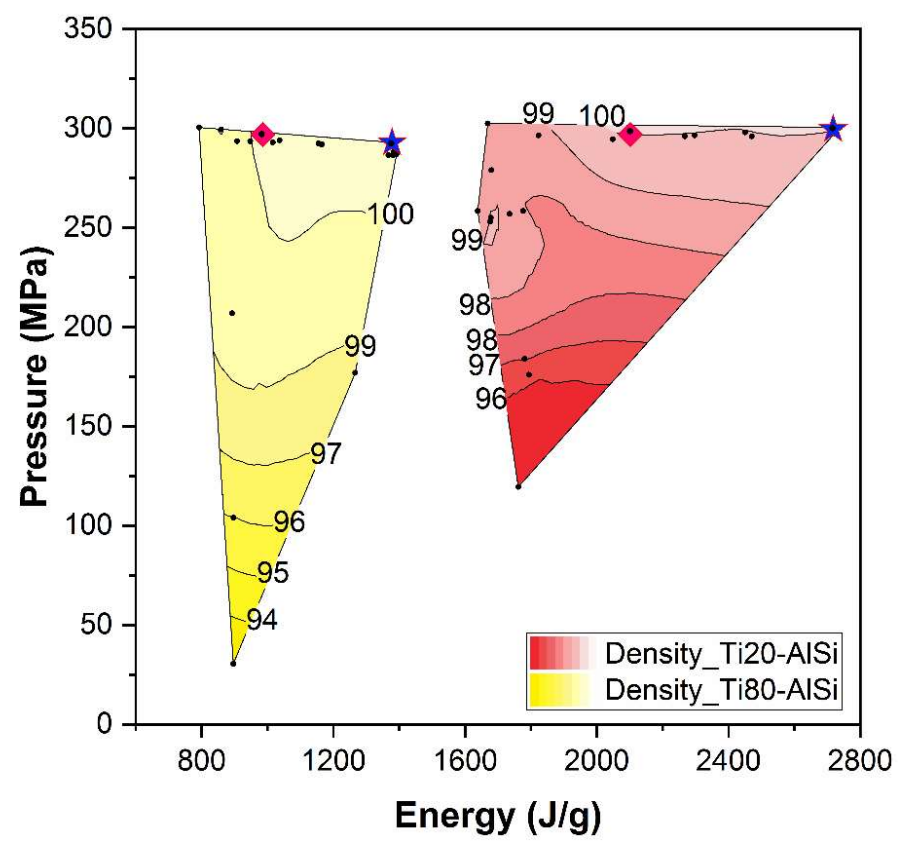

Figure 1. Processing map reporting in isodensity areas, the density measured for each sample produced (black dot). Blue stars identify high-energy samples, while pink diamonds are for low-energy ones. 
As reported in Figure 1, Ti80-AlSi requires lower amounts of energy to be densified up to theoretical density, consequently being more processable. The symbols on the processability map identify the process parameters employed for producing the samples studied in this work. Such parameter is reported in other studies on ESF published by the authors, but for the sake of experimental reproducibility, the matrix, including all the process parameters and the obtained densities, is attached as supplementary material.

Samples were Electro-Sinter-Forged in without any protective atmosphere. Due to the shallow process time (in the order of a few $\mathrm{ms}$ ), the sintered material does not suffer from oxidation or compositional alteration at the surface. Therefore, it was also not possible to acquire a meaningful temperature profile during the process [17]. A heterogeneous temperature profile that is related to the current path through the powders is characteristic of ESF. For this reason, it would not be significant to measure temperature just on the core of the sample. Furthermore, the process itself is so fast that a thermocouple would not be meaningfully responsive in such a narrow process window [20].

The sample's density has been calculated using the geometrical method as the ratio between the volume measured with a high-precision gauge (Mitutoyo Digimatic Micrometer 293) and the weight measured with a high precision scale (Kern PNJ 600-3M) and then compared to the theoretical density for the two compositions, $4.13 \mathrm{~g} / \mathrm{cm}^{3}$ for the Ti80AlSi and $3.04 \mathrm{~g} / \mathrm{cm}^{3}$ for the Ti20-AlSi respectively.

Overall, twenty specimens for each composition were produced by changing ESF process parameters such as pressure and applied energy, as shown in Figure 1.

Each batch of powders was mixed by manual stirring without any protective atmosphere or process control agent (PCA) to exclude carbide formation during sintering [21] (Figure 2); powders were then poured into the die and densified by the coupled application of a capacitive electric discharge and mechanical pressure, i.e., Electro Sinter Forged.

Processing parameters were changed to reach the theoretical density with the lowest level of current possible. The optimized processing parameters were then used to replicate fully dense samples employed for characterization purposes.
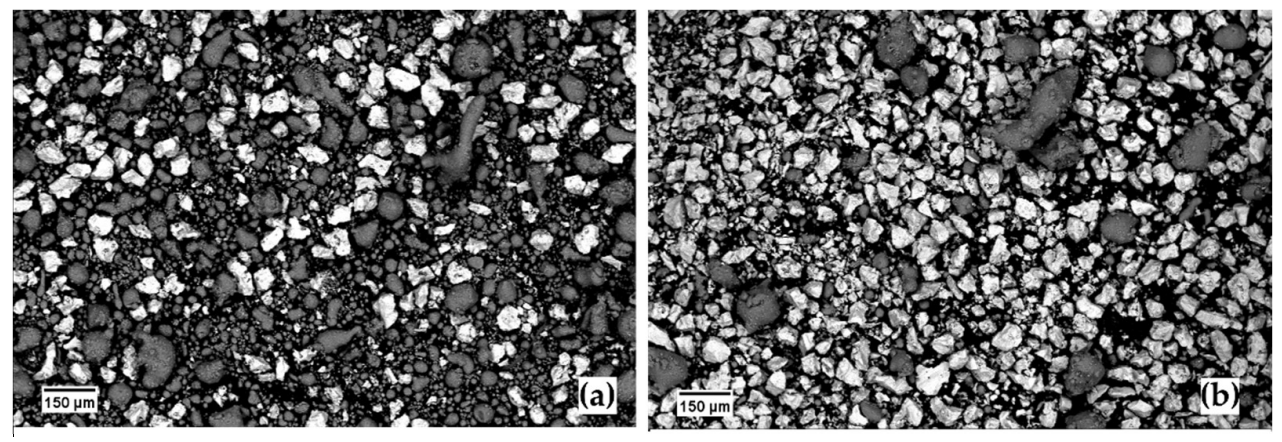

Figure 2. SEM micrograph of the two batches of powders after manual mixing (a) 20Ti-AlSi; (b) 80Ti-AlSi

\subsection{Microstructural, compositional, and hardness characterization}

The microstructural evaluation of the metal-metal composites was carried out by scanning electron microscopy (SEM; Zeiss Evo 15). In addition, an energy dispersive spectroscopy probe (EDS; Oxford Ultim Max) was used to detect compositional variations in the observed microstructures. The microstructures of two dense samples per composition were assessed to evaluate the microstructural influence of low or high current levels. In detail, the two levels of energy analyzed for 20Ti-AlSi dense samples are $1822 \mathrm{~J} / \mathrm{g}$ (low) and $2738 \mathrm{~J} / \mathrm{g}$ (high), while for the $80 \mathrm{Ti}-\mathrm{AlSi}$, they are $860 \mathrm{~J} / \mathrm{g}$ (low) and $1393 \mathrm{~J} / \mathrm{g}$ (high). In addition, light elements such as $\mathrm{O}, \mathrm{N}, \mathrm{H}$, and $\mathrm{C}$ were quantified in both the powders and ESFed samples through LECO elemental analyzers ONH 836 and CS 744. 
One sample per composition among the low-energy densest ones was tested by differential scanning calorimetry (DSC; Setaram DSC-TGA 92 16.18); the baseline was then removed by the software OriginLab. Samples with comparable masses $(0.0515 \mathrm{~g}$ for Ti20AlSi and $0.0385 \mathrm{~g}$ for Ti80-AlSi) were heated under an Ar shielding atmosphere to $800^{\circ} \mathrm{C}$ at a $10 \mathrm{~K} / \mathrm{min}$ heating rate and cooled at the same rate under the same shielding atmosphere. This temperature was chosen since it is significantly higher than the expected liquidus temperature for AlSi10Mg. Each experiment was repeated twice on the same sample to observe the modification in the transformation temperatures of each composition after the first heating. In addition, the sample's microstructures were observed after the calorimetric analysis to support the interpretation of the experimental data.

Due to the high amount of energy imparted to the powders during ESF, the metallurgical phases in the material are not known a priori. Therefore, phases were identified by X-ray diffraction (XRD; PANalytical/X'Pert 3 Pro) under Cu-Ka radiation (1.541874 Å) at $45 \mathrm{kV}$ and $40 \mathrm{~mA}$. XRD patterns were recorded in the $2 \theta$ range of $20-90^{\circ}$ with $0.01^{\circ}$ step size and 1 s time step. One dense sample per composition was analyzed among those processed at high energy.

Microhardness (MicroHV; Leica VMHT) was measured to evaluate the different $\mathrm{Al} / \mathrm{Ti}$ ratios' influence on the as-ESFed material's final hardness. Two 5 X 5 indentation matrices were made with a $25 \mathrm{gf}$ load and an indenting time of $15 \mathrm{~s}$. The measured microhardness values were used to build a map correlating to the microstructure (OriginLab). Image J open-source software was adopted to measure the Ti particles mean free-path in the as-sintered samples [22,23].

\section{Results}

\subsection{Interstitial elements concentration and XRD analysis}

As observed in previous research on Nitinol [17] and on a modified 100Cr6 [18], employing a rapid capacitive sintering process where powders are enclosed in a confined die helps hinder the reactivity of the processed powders with the environmental atmosphere. The fraction of light elements such as $\mathrm{O}, \mathrm{N}, \mathrm{H}$, and $\mathrm{C}$ does not differ significantly from powders to dense material (Table 2); the pre and post-sintered values are, in fact, comparable if uncertainty is taken into account.

Table 2. Interstitial O, N, H, and C concentrations for powders and dense samples of Ti20-AlSi and Ti80-AlSi

\begin{tabular}{ccccccccc}
\hline & \multicolumn{2}{c}{ O [\%] } & \multicolumn{2}{c}{$\mathbf{N}[\%]$} & \multicolumn{2}{c}{ H [ppm] } & \multicolumn{2}{c}{ C [\%] } \\
\hline & Powder & ESFed & Powder & ESFed & Powder & ESFed & Powder & ESFed \\
Ti20-A1Si & $0.16 \pm 0.02$ & $0.16 \pm 0.01$ & $0.005 \pm 0.002$ & $0.005 \pm 0.002$ & $63 \pm 5$ & $64 \pm 6$ & $0.016 \pm$ & $0.015 \pm$ \\
& & & & & & 0.002 & 0.003 \\
Ti80-A1Si & $0.21 \pm 0.01$ & $0.21 \pm 0.02$ & $0.006 \pm 0.002$ & $0.004 \pm 0.002$ & $132 \pm 8$ & $131 \pm 7$ & $0.014 \pm$ & $0.013 \pm$ \\
& & & & & & & & \\
\end{tabular}

On the other side, the difference between the $\mathrm{H}$ intake in the two powder mixtures is significant. It correlates to the starting powder's state; indeed, no significant variation in $\mathrm{H}$ concentration is observed after processing. Such $\mathrm{H}$ levels can be attributed to the $\mathrm{Ti}^{-}$ powders; actually, they are produced by a hydride - dehydride (HDH) process reported by the producer, which might have left some trace of hydrogen in the Ti powders.

The analysis of the XRD patterns presented in Figure 3 highlights the presence of $\alpha$ $\mathrm{Ti}, \mathrm{Al}$, and $\mathrm{Si}$, with more intense peaks related to the predominant phases contained in each metal-metal composite. The Si-related peaks are evident in the 20Ti-AlSi sample only; Si represents a small percentage of the overall composite. The peaks characteristic for $\mathrm{Al}_{3} \mathrm{Ti}$ [11] are not detectable in the XRD spectrum, so, at this stage, the formation of 
intermetallic compounds can be partially discarded. XRD has limited sensitivity in detecting phases with a volumic fraction smaller than $2 \%$ [24], depending on the type of equipment; further confirmations supporting the formation of reacted layer between $\mathrm{AlSi} 10 \mathrm{Mg}$ and CP-Ti can descend from the microstructural observations.

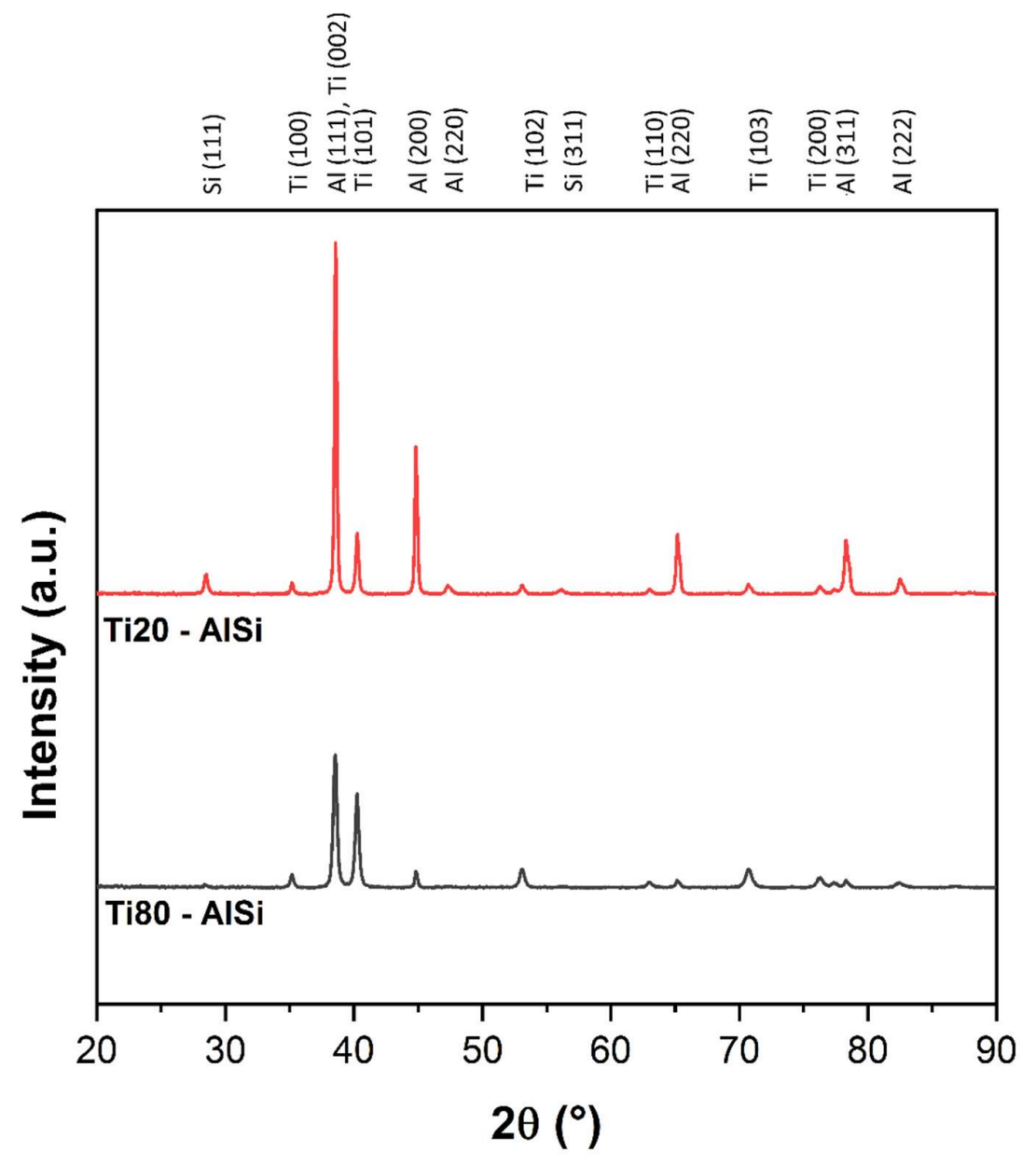

Figure 3. XRD diffraction patterns for the Ti20-AlSi and Ti80-AlSi dense samples.

\subsection{Microstructural analysis of the as-ESFed material}

The microstructure of the powders treated by ESF at high energy is characterized by two distinct domains carrying the composition of the starting powders (Figure 4). At low magnification, such evidence is witnessed by the morphology (secondary electrons, Figure 4. (a) and (b)), the chemical composition (backscattered electrons, Figure 4. (c) and (d)), and the chemical analysis (electron dispersive spectroscopy, Figure 4. (e) and (f). The aluminum-based phase (dark phase) constitutes a continuous three-dimensional network acting as a matrix surrounding the $\alpha$-Ti grains that have preserved their original blocky and angular shape. In the Ti20-A1Si metal-metal composite (Figure 4. (a), (c) and (e)), the $\alpha$-Ti particles are randomly dispersed with an average free mean path of $75.2 \pm 18.4 \mu \mathrm{m}$; the same configuration is also observed in the Ti80-AlSi sample (Figure 4. (b), (d) and (f)) but in this case, the mean free path separating the $\alpha$-Ti particles is significantly reduced, and it is equal to $5.4 \pm 0.9 \mu \mathrm{m}$. Thus, the ESF process does not significantly alter the average Ti particle size from the starting one. Such evidence suggests that even the pre-compres- 
sion applied to the loose powders system does not crush Ti powders but realistically deforms the softer AlSi10Mg powders reducing the green porosity before the electric current is discharged through the material.
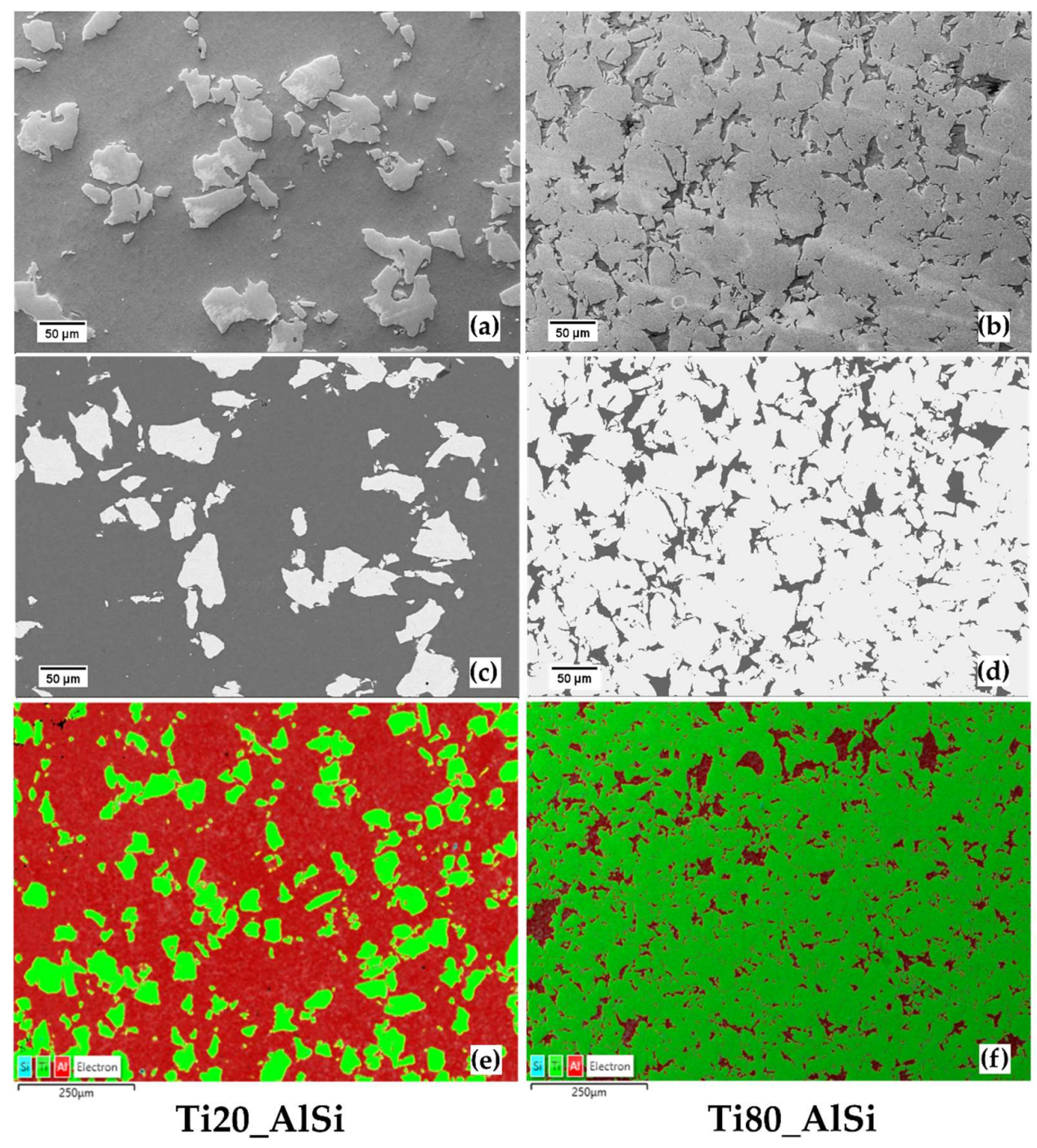

Figure 4. SEM micrograph of the samples ESFed at high energy. (a) and (b) are secondary electron SEM images, (c) and (d) are back-scattered electrons (BSE) images, (e) and (f) are EDS maps at low magnification.

The absence of other phases besides the $\alpha$-Ti and the AlSi10Mg domains is confirmed even at higher magnifications for low-energy samples (Figure 5. (a) and (b)). However, when high-energy samples are considered (Figure 5. (c), (d)), the two systems behave differently. Samples with high AlSi concentration still show a dual-phase composition (Figure 5. (c), Ti20-AlSi), while in samples with low AlSi concentration, needle-like particles indicated by arrows in Figure 5 (d) are located in confined AlSi isles and preferentially decorating the edges of the $\alpha$-Ti domains (Figure 5. (d)). The EDS line analysis of needleshaped particles shows a local peak in Titanium concentration when crossing the investigated particle while the Aluminum and Silicon signals remain quasi-constant (Figure 5 (f)). The analysis has been performed on an isolated particle to maximize the compositional information when crossing the region of interest; these particles are assumed to be a reacted layer between $\mathrm{Ti}$ and AlSi10Mg powders formed due to the current-induced 
heating. The reacted layer was analyzed by point analysis to give a more accurate and quantitative evaluation of its composition; that result is given in Table 3. Since such needle-shaped particles are observable in the high-energy 80Ti-AlSi only, the two high-energy systems were then compared based on DSC.
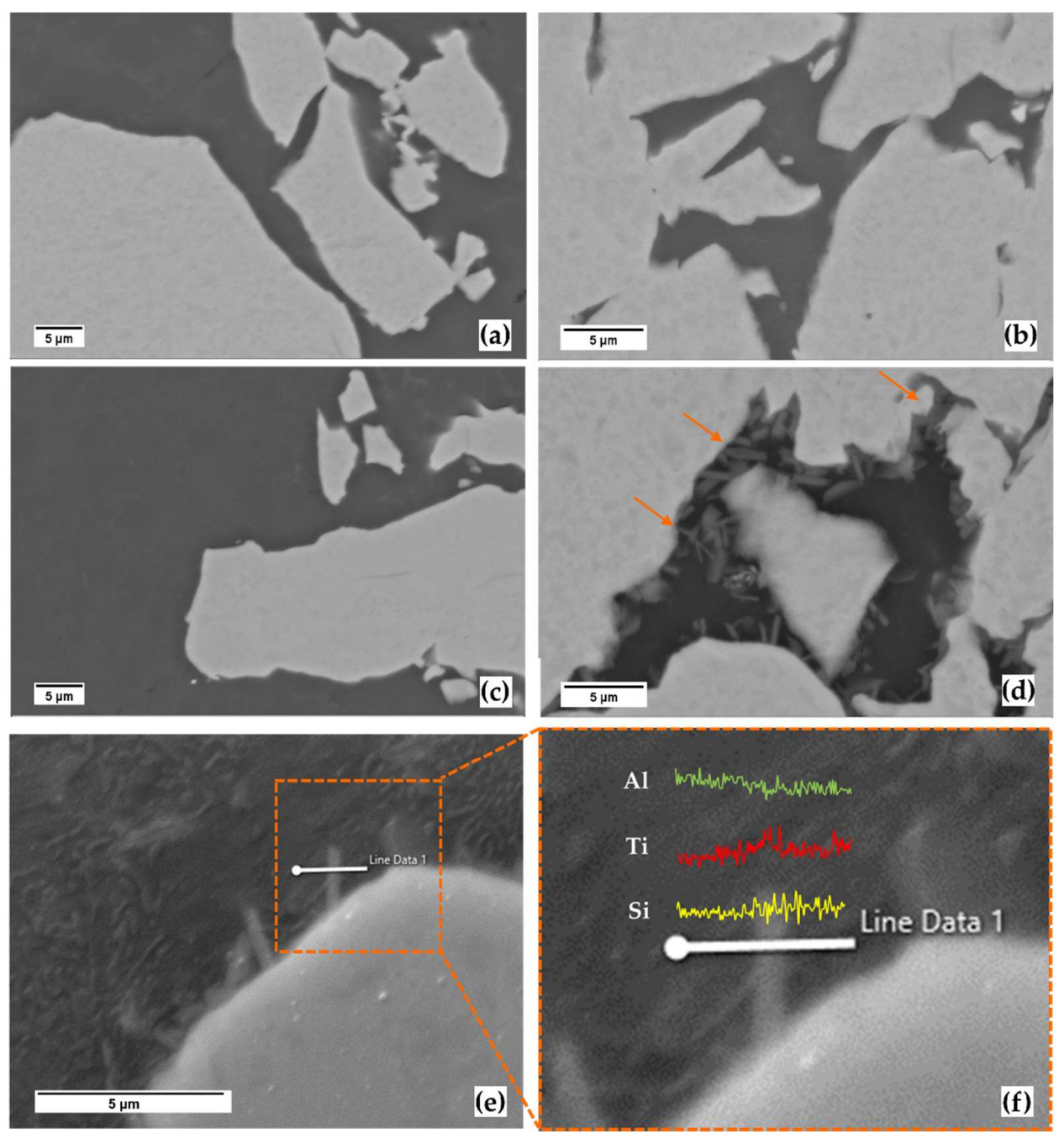

Figure 5. BSE-SEM micrograph of the ESFed samples. (a) and (b) micrographs are the low energy samples respectively from the 20Ti-AlSi, and the 80Ti-AlSi powders mix, (c) and (d) are the high energy samples respectively $20 \mathrm{Ti}-\mathrm{AlSi}$ and $80 \mathrm{Ti}-\mathrm{AlSi}$, (e) and (f) is the result of an EDS analysis on an intermetallic particle. Orange arrows in (d) underline the presence of needle-shaped particles in AlSi10Mg isles.

Table 3. Composition after EDS point analysis of the reacted layer.

\begin{tabular}{llll}
\hline & Al [\%wt] & Ti [\%wt] & Si [\%wt] \\
\hline Reacted layer & $79.54 \pm 0.43$ & $11.86 \pm 0.14$ & $7.50 \pm 0.94$ \\
\hline
\end{tabular}

The calorimetric analysis was performed up to $800^{\circ} \mathrm{C}$ to promote the formation of intermetallic compounds in the tested sample. As observed in Figure 6. (a) and (b), the endothermic peaks characteristic for the eutectic transformation $\left(577^{\circ} \mathrm{C}\right)$ and the liquidus curve $\left(602^{\circ} \mathrm{C}\right)$ of the AlSi10 system are detected in both metal-metal composite materials. Titanium, on the contrary, does not transform in the $200-800^{\circ} \mathrm{C}$ interval indeed the $\alpha \rightarrow$ 
$\beta$ transformation is known to occur at $881^{\circ} \mathrm{C}$. Finally, the onset of a broad exothermic peak occurs at $650^{\circ} \mathrm{C}$, in a range compatible with the energy released due to the formation of Al-Ti-based intermetallic compounds [12] [25] [26]. The intensity of this last peak is related to the quantity of AlSi10Mg ready to react with Ti. This peak is higher for Ti20-AlSi, where AlSi10Mg is $80 \%$ vol.

In contrast, it is lower for Ti80-AlSi, where AlSi10Mg is $20 \%$ vol. The observation of the two samples after DSC shows a modified microstructure compared to the as-ESFed materials (Figure 6 (c) and (d)). Al, Si, and Ti reacted, forming new grains of complex AlTiSi based intermetallic compounds. However, some traces of Aluminum and Titanium are still observable in the microstructures. Titanium, in particular, was not found in the Ti20-AlSi sample after DSC, while Al traces are still detectable (Figure 6. (e)). The material in the as-ESFed condition is thermodynamically stable until the complete melting of AlSi10Mg occurs, and intermetallic phases are abundantly formed with a dissolution mechanism. The elevated surface-to-volume ratio of the Ti particles embedded in the AlSi10Mg matrix causes the reaction to travel fast. The granular morphology of the AlTiSi grains, which are kept together by a thin Aluminum film (Figure 6. (e)), is supposed to be related to the formation of the intermetallic compounds acting by a progressive reaction and separation process. Further details regarding the formation mechanisms of Al-Ti intermetallics between molten $\mathrm{Al}$ and solid $\mathrm{Ti}$ in a range of temperatures comparable with that of the current study are presented in [27].
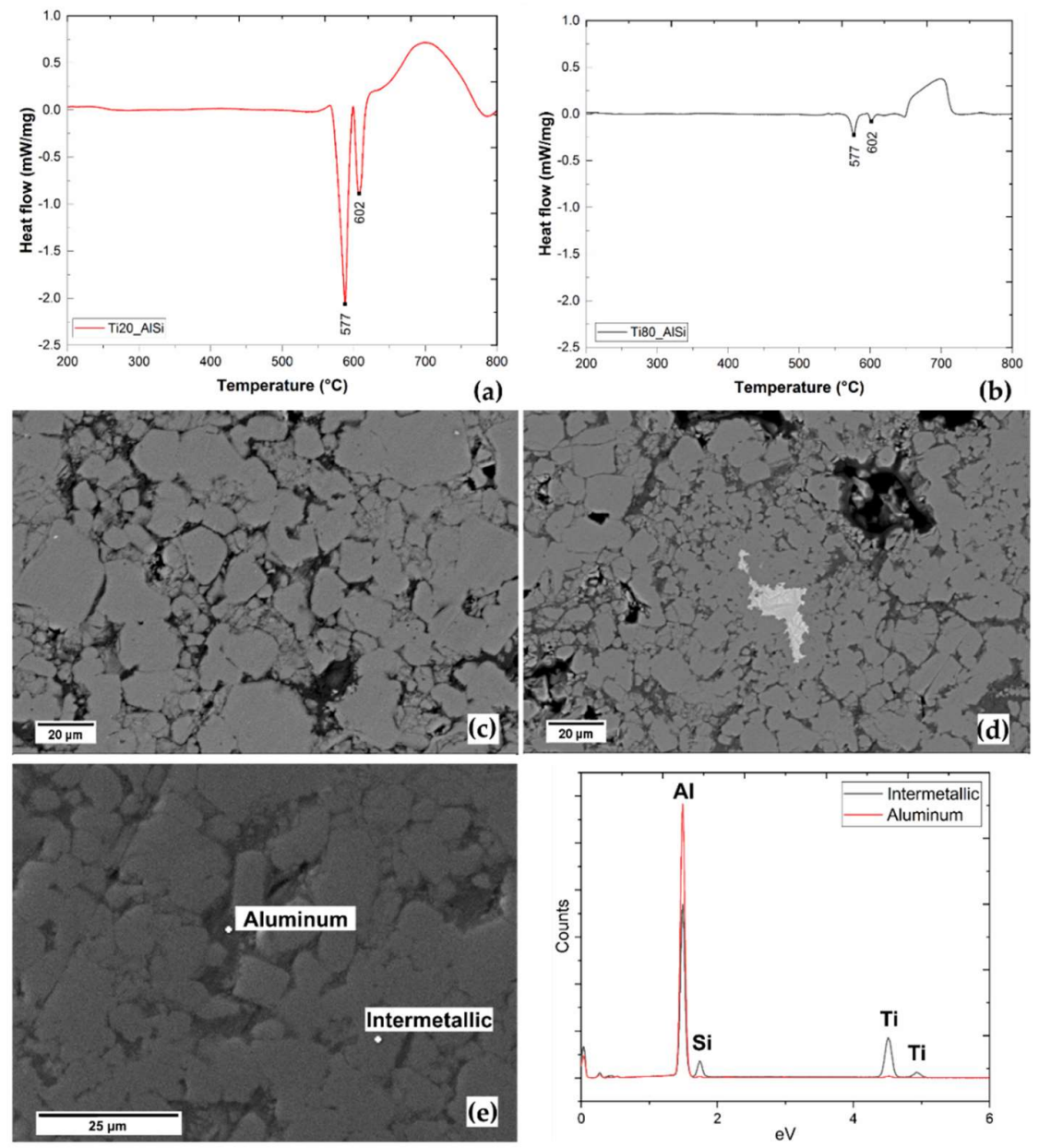

Figure 6. DSC and SEM/EDS analysis. (a) and (b) are the calorimetric analysis for Ti20_AlSi and Ti80_AlSi, respectively; (c) and (d) are BSE images of the microstructures after DSC; (e) EDS analysis of the Ti20-AlSi sample after DSC. 
Microhardness measurements give preliminary data regarding mechanical properties (Figure 7.). Microhardness mappings help to observe the difference between the two composites. For example, Ti20-AlSi is characterized by a lower average microhardness $(113 \pm 13 \mathrm{HV})$ and a non-normally distributed hardness measured along the region of measurement (p-value $<0.005$ for Anderson-Darling normality test in Figure 7(c) with $\alpha$ level 0.10). In addition, two peaks are observed in Figure 7(c) inset, indicating a separate contribution of the two phases $(\alpha$-Ti and AlSi10Mg). This effect is similar to that of a harder phase dispersed in a softer one. Based on previous investigations [28], the electrosinter-forged AlSi10Mg powders are rapidly molten and then solidified during sintering; the alloy is in the solubilized state and can be heat-treated to increase mechanical properties through an artificial age hardening.

Conversely, Ti80-AlSi is characterized by a higher average microhardness $(244 \pm 35$ $\mathrm{HV})$. At this load, the two contributions are not disjointed, and the hardness values appear to be normally distributed ( $\mathrm{p}$-value $=0.238$ at $\alpha$-level 0.10 for Anderson-Darling normality test, Figure 7(d)) with a monomodal shape. This effect is conceptually similar to composite materials such as cemented carbides, where the hard phase is predominant in volume fraction, and the soft phase is the binder.
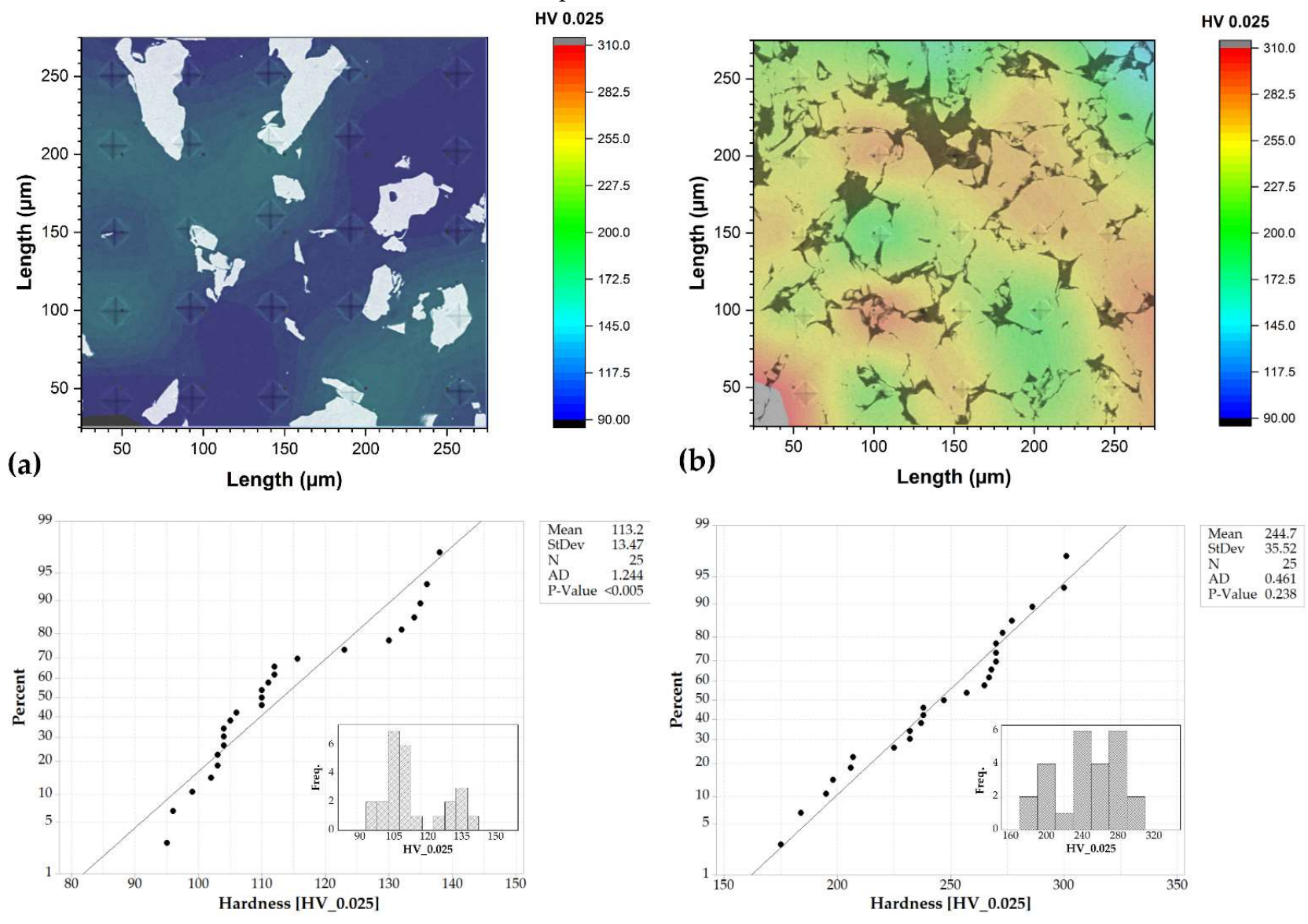

(c)

(d)

Figure 7. Microhardness mapping and statistical data distribution. (a) and (c) refer to the Ti20-AlSi composite, while (b) and (d) refer to the Ti80-AlSi composite.

\section{Discussion}

4.1 Densification mechanism and resistivity of the Ti/AlSi10Mg powders 
ESF is a pressure-assisted capacitive-discharge sintering process, and the mutual contribution of electric current, primarily and pressure secondly, must be considered when attempting to explain what happens during densification. Moreover, besides process-related features, the interaction with metal powders changes as a function of the processed material. For example, considering the mixed Ti/AlSi10Mg powders, every single grain of powder brings the electrical and mechanical properties of the parent material; for this reason, the interactions between AlSi10Mg powders, Ti powders, and electrical current need further discussion.

\subsubsection{Continuum approach}

The first, simplistic approach towards the problem of densification in ESF, and generally for other electrical-field assisted sintering techniques, would be considering the powders as having the same electrical properties of the solid continuum. As reported in Figure 8, the resistivity of pure $\mathrm{Ti}$ is considerably higher than for AlSi10Mg. When the $\mathrm{Al}$ alloy reaches the molten state, Ti has a resistivity of two orders in magnitude higher that is then mildly reduced by the $\alpha \rightarrow \beta$ transformation at $882^{\circ} \mathrm{C}$.

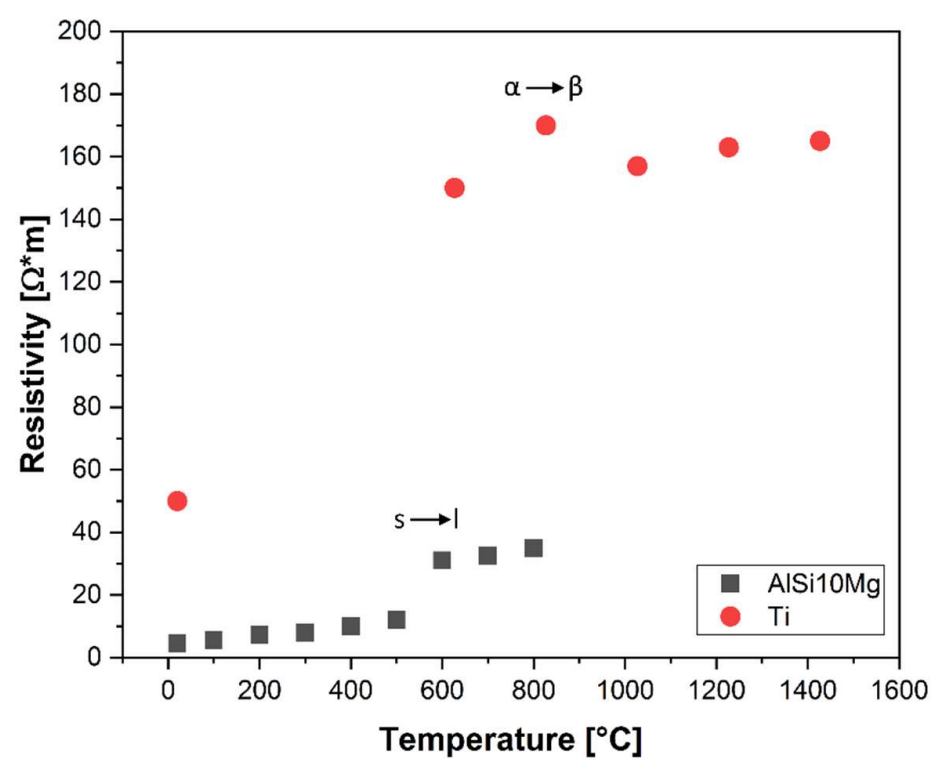

Figure 8. Electrical resistivity as a function of Temperature for AlSi10Mg [29] and Ti [30]. Data in the graph were multiplied by $10^{8}$.

By accepting the above-stated continuum assumption, the path of the electric current would be confined preferentially through the AlSi10Mg powder; indeed, the electric current would not travel through Ti due to its higher resistivity. The amount of energy $(\mathrm{kJ} / \mathrm{g}$ ) imparted to the system causes the $\mathrm{Al}$ alloy to melt and fill the pores by the simultaneous action of the applied pressure.

If the AlSi10Mg fraction is considered as the preferential path for the current flow, the specific amount of energy concentrating through it is defined as:

$$
E_{\text {specific }}=\frac{E}{\text { vol.fraction }_{\text {Alsi } 10 \mathrm{Mg}}}
$$

The calculated specific energies reported in Table 4 are a piece of further evidence supporting the reaction at the Ti/AlSi10Mg interface in the high-energy Ti80-AlSi sample. The energy necessary to densify the starting powders is lower for the Ti80-AlSi system ( 0.86 and $1.39 \mathrm{~kJ} / \mathrm{g}$ for low and high-energy) because of the lower amount of AlSi10Mg to densify; nevertheless, if specific energy is compared for high-energy samples, its value is 
double for Ti80-AlSi (3.42 kJ/g for Ti20-AlSi vs. $6.95 \mathrm{~kJ} / \mathrm{g}$ for Ti80-AlSi). Such an energetic surplus is responsible for the reaction occurring between Ti and AlSi10Mg. Compared to the data reported by Adeli et al. [26], some similarities can be found in the energetic approach. Activation energies spanning between 210.9 and $215.8 \mathrm{~kJ} / \mathrm{mol}$ are presented for the formation of TiAl starting from an equiatomic Ti-Al powder mix. Such activation energies range between 5.65 and $5.77 \mathrm{~kJ} / \mathrm{g}$, with a value comparable to those reported in Table 4. More in detail, considering the $5.65-5.77 \mathrm{~kJ} / \mathrm{g}$ range, such values are lower than the $6.965 \mathrm{~kJ} / \mathrm{g}$ corresponding to the formation of intermetallics observed in the high energy Ti80-AlSi sample. As low energy samples regards, based on the observation reported in [31], it is supposed that intermetallics do not form in low energy samples despite the possible melting of AlSi10Mg, due to the competition between kinetics and thermodynamics. Diffusional mechanisms necessary to form intermetallic compounds at the Ti/Al interface are temperature-activated but time-regulated, and eventually, the ESF consolidation process lasts for a fraction of a second.

Table 4. Energy values as calculated from the experimental data and specific energy flowing through the AlSi10Mg phase.

\begin{tabular}{ccccc}
\hline & \multicolumn{2}{c}{ Ti20-A1Si } & \multicolumn{2}{c}{ Ti80-A1Si } \\
\hline & Low & High & Low & High \\
$\mathrm{E}[\mathrm{kJ} / \mathrm{g}]$ & 1.822 & 2.738 & 0.860 & 1.393 \\
Especific $[\mathrm{kJ} / \mathrm{g}]$ & 2.277 & 3.422 & 4.300 & 6.965 \\
\hline
\end{tabular}

4.1.3 Discrete approach

The more complex but rigorous approach implies considering the pre-sintered powders as a discrete set of particles where three types of contacts characterize the whole volume: 1- AlSi10Mg-Ti, 2- Ti-Ti, and 3- AlSi10Mg-AlSi10Mg. The pre-sintered volume has a certain degree of porosity depending on the powder's tap density.

In literature, this discrete approach has been treated and modeled by several researchers. The model developed by Montes and co-workers [32], who developed a simplified model to describe the resistivity of powder systems as a function of the degree of porosity, is exploited hereafter. This model is devoted explicitly to describing the electrically-assisted consolidation techniques for metallic powders, commonly known as fieldassisted sintering techniques (FAST). Two relations are proposed to describe the effective resistivity for oxide-free (2) or oxide-coated particles (3), with (2) being a particular case derivable from (3).

$$
\begin{aligned}
& \rho_{E}=\rho_{0}\left(1-\frac{\Theta}{\Theta_{M}}\right)^{-\frac{3}{2}} \\
& \rho_{E}=\rho_{\text {res }}\left(1-\frac{\Theta}{\Theta_{M}}\right)^{-n}
\end{aligned}
$$

Qo is the bulk resistivity, @resis the residual resistivity (higher or equal to @o) due to the presence of a thin oxide layer on the particle's surface, $\Theta$ is the degree of porosity of the powder system, and it is the variable in the equation, $\Theta_{\mathrm{M}}$ is the tap porosity of the powder system considered, and $n$ is a fitting parameter describing the oxide descaling rate.

During ESF, the powders are compacted and sintered by the superimposed application of current and pressure; nevertheless, before discharging the energy stored in the capacitor bank, a starting pressure of $15 \mathrm{MPa}$ was applied to the loose powders promoting the oxide layer to break up. Therefore, we can assume that applying a pre-ESF compression reduces the porosity of the loose powder compact and deforms the softer AlSi10Mg 
powders breaking a large portion of the thin oxide layer that naturally covers metal powders.

As for the continuum approach, the focus is on AlSi10Mg-AlSi10Mg contacts occurring on descaled surfaces for the aforementioned assumption; the relative electrical resistivity as a function of porosity has been calculated for the deoxidized Ti-Ti contact for the sake of comparison. In addition, AlSi10Mg-Ti and Ti-Ti resistivity should also be analyzed, but the flow of electricity is not favored in these configurations; however, the models for calculating composite resistivity for AlSi10Mg-Ti contact are given in [33].

Given the fraction of tap porosity as

$$
\Theta_{M}=1-\frac{\text { tap density }}{\text { solid density }}
$$

With a solid density equal to $2.59 \mathrm{~g} / \mathrm{cm}^{3}$ for the AlSi10Mg alloy and $4.50 \mathrm{~g} / \mathrm{cm}^{3}$ for pure $\mathrm{Ti}$, the graph in Figure 8 is calculated based on (2).

Based on (2), the effective resistivity increases with increasing porosity of the powder system and tends asymptotically to infinite for a degree of porosity equal to $\Theta_{\mathrm{M}}$. The model developed by Montes further confirms the hypothesis of current mainly flowing through the AlSi10Mg powders with a strong dependence on the initial tap porosity value on the asymptote. Nevertheless, the Joule effect in the electrically conducting powders is noticeably higher when a certain amount of residual porosity still has to be eliminated, thus causing the temperature to rise. This mechanism constitutes the driving force locally heating the AlSi10Mg domains and causing AlSi10Mg-Ti surface reaction, depending on the specific energy imparted.

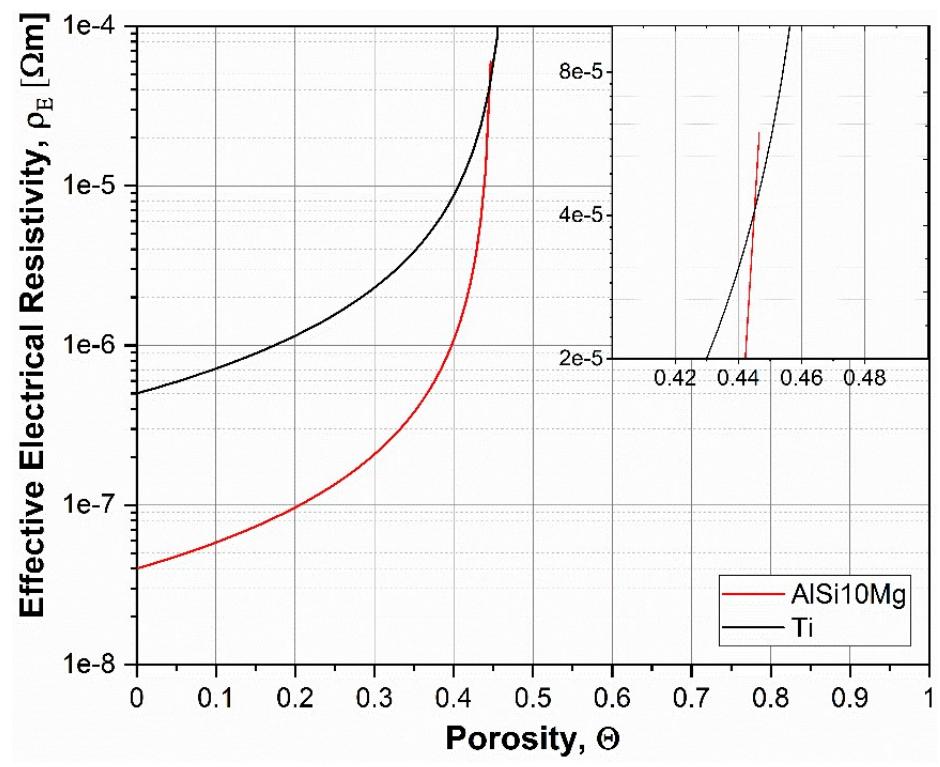

Figure 8. Effective electrical resistivity as calculated for AlSi10Mg and CP-Ti powders.

\section{Conclusions}

In the present study, the sinterability of a near-net-shape Ti/AlSi10Mg metal-metal composite obtained via a field-assisted rapid sintering technique named electro-sinterforging is presented for the first time. Furthermore, it has been proved that operating in specific pressure and energy conditions can result in the densification of a metal-metal 
composite where the only detectable phases are those constituting the starting powders: $\mathrm{Ti}$ and AlSi10Mg, respectively.

By properly tuning the amount of specific energy imparted to the powder system, the dissolution of Ti from the powder's surface can be promoted; such an outcome can be a further challenge for the production of near-net-shape intermetallic parts.

Finally, the preferential path of the electric current through the AlSi10Mg powders was confirmed on the experimental and theoretical sides by the microstructural observations and the discussion of the models for characterizing powder systems resistivity.

Author Contributions: The following statements should be used "Conceptualization, A.F., and F.S.G.; methodology, F.S.G.; formal analysis, F.S.G., and E.F.; investigation, F.S.G., E.F., and A.F.; resources, M.A.G.; data curation, F.S.G., and E.F.; writing-original draft preparation, F.S.G.; writing-review and editing, E.F. and I.P..; supervision, M.A.G, and I.P. All authors have read and agreed to the published version of the manuscript."

Funding: This research received no external funding

Data Availability Statement: In this section, please provide details regarding where data supporting reported results can be found, including links to publicly archived datasets analyzed or generated during the study. Please refer to suggested Data Availability Statements in the section "MDPI Research Data Policies" at https://www.mdpi.com/ethics. You might choose to exclude this statement if the study did not report any data.

Acknowledgments: The authors are grateful to Ing. Enrico Pallavicini and Ing. Dario Pezzini for their valuable help in sample preparation and the support during the analysis.

Conflicts of Interest: The authors declare no conflict of interest

\section{References}

1. Albert, T.; Sunil, J.; Christopher, A.S.; Jegan, R.; Prabhu, P.A.; Selvaganesan, M. Preparation and characterization of aluminium-titanium carbide (Al-TiC) composite using powder metallurgy. In Proceedings of the Materials Today: Proceedings; 2020; Vol. 37.

2. Sidambe, A.T.; Figueroa, I.A.; Hamilton, H.G.C.; Todd, I. Metal injection moulding of CP-Ti components for biomedical applications. J. Mater. Process. Technol. 2012, 212, doi:10.1016/j.jmatprotec.2012.03.001.

3. Singh, H.; Singh Brar, G.; Kumar, H.; Aggarwal, V. A review on metal matrix composite for automobile applications. In Proceedings of the Materials Today: Proceedings; 2020; Vol. 43.

4. Capus, J. PM light alloys gaining applications in automotive sector. Met. Powder Rep. 2013, 68, 12-15, doi:10.1016/S00260657(13)70210-8.

5. Chaira, D. Powder Metallurgy Routes for Composite Materials Production. Encycl. Mater. Compos. 2021, 588-604, doi:10.1016/b978-0-12-803581-8.11703-5.

6. Hassan, S.F.; Gupta, M. Development of ductile magnesium composite materials using titanium as reinforcement. J. Alloys Compd. 2002, 345, doi:10.1016/S0925-8388(02)00413-9.

7. Balarami Reddy, T.; Karthik, P.; Gopi Krishna, M. Mechanical behavior of Al-Cu binary alloy system/ Cu particulates reinforced metal-metal composites. Results Eng. 2019, 4, doi:10.1016/j.rineng.2019.100046.

8. Canakc1, A.; Ozkaya, S.; Erdemir, F.; Karabacak, A.H.; Celebi, M. Effects of Fe-Al intermetallic compounds on the wear and corrosion performances of AA2024/316L SS metal/metal composites. J. Alloys Compd. 2020, 845, doi:10.1016/j.jallcom.2020.156236.

9. Gopi Krishna, M.; Praveen Kumar, K.; Naga Swapna, M.; Babu Rao, J.; Bhargava, N.R.M.R. Metal-metal Composites-An Innovative Way for Multiple Strengthening. Mater. Today Proc. 2017, 4, 8085-8095, doi:10.1016/j.matpr.2017.07.148.

10. Sun, Y.; Vajpai, S.K.; Ameyama, K.; Ma, C. Fabrication of multilayered Ti-Al intermetallics by spark plasma sintering. J. Alloys Compd. 2014, 585, 734-740, doi:10.1016/j.jallcom.2013.09.215. 
11. Peng, L.M.; Wang, J.H.; Li, H.; Zhao, J.H.; He, L.H. Synthesis and microstructural characterization of Ti-Al3Ti metalintermetallic laminate (MIL) composites. Scr. Mater. 2005, 52, 243-248, doi:10.1016/j.scriptamat.2004.09.010.

12. Luo, J.G.; Acoff, V.L. Using cold roll bonding and annealing to process Ti/Al multilayered composites from elemental foils. Mater. Sci. Eng. A 2004, 379, 164-172, doi:10.1016/j.msea.2004.01.021.

13. Huang, M.; Fan, G.H.; Geng, L.; Cao, G.J.; Du, Y.; Wu, H.; Zhang, T.T.; Kang, H.J.; Wang, T.M.; Du, G.H.; et al. Revealing extraordinary tensile plasticity in layered Ti-Al metal composite. Sci. Rep. 2016, 6, doi:10.1038/srep38461.

14. Fais, A. A faster FAST: Electro-Sinter-Forging. Met. Powder Rep. 2018, 73, 80-86, doi:10.1016/j.mprp.2017.06.001.

15. Forno, I.; Actis Grande, M.; Fais, A. On the application of Electro-sinter-forging to the sintering of high-karatage gold powders. Gold Bull. 2015, 48, 127-133, doi:10.1007/s13404-015-0169-x.

16. Fais, A.; Actis Grande, M.; Forno, I. Influence of processing parameters on the mechanical properties of Electro-Sinter-Forged iron based powders. Mater. Des. 2016, 93, 458-466, doi:10.1016/j.matdes.2015.12.142.

17. Balagna, C.; Fais, A.; Brunelli, K.; Peruzzo, L.; Horynová, M.; Čelko, L.; Spriano, S. Electro-sinter-forged Ni-Ti alloy. Intermetallics 2016, 68, 31-41, doi:10.1016/j.intermet.2015.08.016.

18. Gobber, F.S.; Bidulská, J.; Fais, A.; Bidulský, R.; Grande, M.A. Innovative densification process of a fe-cr-c powder metallurgy steel. Metals (Basel). 2021, 11, doi:10.3390/met11040665.

19. GOBBER, FS; BIDULSKÁ, J; FAIS, A; FRANCHINI, F; BIDULSKÝ, R; KVAKAJ, T; ACTIS GRANDE, M. Characterization of microstructural and mechanical properties after cold rolling of an electro-sinter-forged Cu-Sn alloy. Arch. Metall. Mater. 2020, doi:10.24425/amm.2020.132821.

20. Pavlasek, P.; Elliott, C.J.; Pearce, J. V.; Duris, S.; Palencar, R.; Koval, M.; Machin, G. Hysteresis Effects and Strain-Induced Homogeneity Effects in Base Metal Thermocouples. Int. J. Thermophys. 2015, 36, 467-481, doi:10.1007/s10765-015-1841-3.

21. Lee, W.H.; Cheon, Y.W.; Kim, K.B.; Yoon, Y.H.; Jeong, C.H.; Kim, Y.H.; Van Tyne, C.J.; Chang, S.Y. Carbide formation in electric-discharge-sintered Ti3Al compact caused by steric acid in ball-milled Ti and Al powder mixture. Ceram. Int. 2018, 44, 19771-19778, doi:10.1016/j.ceramint.2018.07.233.

22. Schneider, C.A.; Rasband, W.S.; Eliceiri, K.W. NIH Image to ImageJ: 25 years of image analysis. Nat. Methods 2012, 9, 671675, doi:10.1038/nmeth.2089.

23. Haeri, M.; Haeri, M. ImageJ Plugin for Analysis of Porous Scaffolds used in Tissue Engineering. J. Open Res. Softw. 2015, 3, doi:10.5334/jors.bn.

24. Khan, H.; Yerramilli, A.S.; D'Oliveira, A.; Alford, T.L.; Boffito, D.C.; Patience, G.S. Experimental methods in chemical engineering: X-ray diffraction spectroscopy-XRD. Can. J. Chem. Eng. 2020, 98.

25. Wang, T.; Liu, R.Y.; Zhu, M.L.; Zhang, J.S. Activation energy of self-heating process studied by DSC combustion synthesis mixture of Ti-75 at\% Al. J. Therm. Anal. Calorim. 2002, 70, 507-519, doi:10.1023/A:1021684726126.

26. Adeli, M.; Seyedein, S.H.; Aboutalebi, M.R.; Kobashi, M.; Kanetake, N. Implementation of DSC analysis in reaction kinetics during heating of Ti-50 at.\%Al powder mixture. J. Therm. Anal. Calorim. 2017, 128, 867-874, doi:10.1007/s10973-016-5982-9.

27. Gurevich, L.M.; Shmorgun, V.G. Intermetallic Compound Formation During Reaction of Molten Aluminum with Titanium. Metallurgist 2016, 59, 1221-1227, doi:10.1007/s11015-016-0241-7.

28. Fais, A.; Gobber, F.; Rampin, I.; Bidulsky, R.; Grande, M.A. E-Forging ${ }^{\mathrm{TM}}$ AlSi10 and AlSi10Mg0.4 powders with two distinct particle sizes. In Proceedings of the Euro PM 2019 Congress and Exhibition; 2019.

29. Brandt, R.; Neuer, G. Electrical Resistivity and Thermal Conductivity of Pure Aluminum and Aluminum Alloys up to and above the Melting Temperature. Int. J. Thermophys. 2007, 28, 1429-1446, doi:10.1007/s10765-006-0144-0.

30. Bel'skaya, E.A.; Kulyamina, E.Y. Electrical resistivity of titanium in the temperature range from 290 to $1800 \mathrm{~K}$. High Temp. 2007, 45, 785-796, doi:10.1134/S0018151X07060090.

31. Gurevich, L.M.; Shmorgun, V.G. Intermetallic Compound Formation During Reaction of Molten Aluminum with Titanium. 
Metallurgist 2016, 59, 1221-1227, doi:10.1007/s11015-016-0241-7.

32. Manuel Montes, J.; Gómez Cuevas, F.; Cintas, J.; Ternero, F.; Sánchez Caballero, E. Electrical Resistivity of Powdered Porous Compacts. In Electrical and Electronic Properties of Materials; IntechOpen, 2019.

33. Zhang, P.; Lau, Y.Y. Scaling laws for electrical contact resistance with dissimilar materials. J. Appl. Phys. 2010, 108, doi:10.1063/1.3457899. 